\title{
Relating Methanol Oxidation to the Structure of Ceria-Supported Vanadia Monolayer Catalysts
}

\author{
H.L. Abbott*, A. Uhl, M. Baron, Y. Lei, R.J. Meyer, D.J. Stacchiola, O. Bondarchuk, \\ S. Shaikhutdinov*, H.-J. Freund \\ Department of Chemical Physics, Fritz Haber Institute of the Max Planck Society, \\ Faradayweg 4-6, Berlin 14195, Germany
}

\begin{abstract}
.
Vanadia "monolayer"-type catalysts supported on reducible oxides such as ceria previously have shown high activity for the selective oxidation of alcohols. Here, a model system consisting of vanadia particles deposited on well-ordered $\mathrm{CeO}_{2}(111)$ thin films has been employed. Scanning tunneling microscopy (STM), photoelectron spectroscopy (PES), and infrared reflection absorption spectroscopy (IRAS) were used to characterize the $\mathrm{VO}_{\mathrm{x}} / \mathrm{CeO}_{2}$ surface as a function of vanadia loading. The formation of isolated monomeric species as well as two-dimensional vanadia islands that wet the ceria support was directly observed by STM. The vanadia species exhibit $\mathrm{V}$ in $\mathrm{a}+5$ oxidation state and expose vanadyl $(\mathrm{V}=\mathrm{O})$ groups with stretching vibrations that blue-shift from $\sim 1005 \mathrm{~cm}^{-1}$, to $\sim 1040 \mathrm{~cm}^{-1}$ with increasing coverage. Temperature programmed desorption (TPD) of methanol revealed three peaks for formaldehyde production. One is correlated with reactivity on the ceria support (565-590 K). Another is correlated with reactivity on large vanadia particles $(475-505 \mathrm{~K})$ similar to that previously observed on vanadia/silica and vanadia/alumina model systems. A low temperature reaction pathway $(\sim 370 \mathrm{~K})$ is observed at low coverage, which is assigned to the reactivity of isolated vanadia species surrounded by a reduced ceria surface. It is concluded that strong support effects reported in the literature for the real catalysts are likely related to the stabilization of small vanadia clusters by reducible oxide supports.
\end{abstract}

Keywords. Vanadia; Ceria; Selective methanol oxidation; Scanning tunneling microscopy; Photoelectron spectroscopy; Infrared spectroscopy.

*Corresponding authors: shamil@fhi-berlin.mpg.de; heather.abbott-lyon@gatech.edu 


\section{Introduction}

The oxidative dehydrogenation (ODH) of methanol is a highly relevant reaction to the chemical industry due to the chemical versatility of the primary product, formaldehyde (FA), which is used in the manufacture of many products for daily life [1, 2]. At present, Ag and a mixed Fe-Mo oxide have been used as industrial catalysts for this reaction (e.g., see [3] and references therein). Despite substantial efforts in research for these catalysts, eminent issues still need to be overcome, namely the minimization of byproduct formation. Vanadium oxides have recently gained considerable attention as promising alternative catalysts, especially in selective oxidation reactions [4-10].

According to the generally accepted mechanism for the ODH of methanol on oxides, methanol first adsorbs on a Lewis acid-base (or cation-anion) site pair. Thereby, the methoxy group is formed on the cation, while the hydrogen atom adsorbs on lattice oxygen to form a surface hydroxyl. Subsequently, one hydrogen atom from the methoxy group is transferred to another lattice oxygen to form a second adsorbed hydroxyl and formaldehyde, which promptly desorbs from the surface. The hydroxyl groups can recombine to restore the lattice oxygen, and a water molecule desorbs. Hence, in the net reaction methanol loses two hydrogen atoms, which are eventually incorporated into a water molecule. The oxygen atom of the water comes from the surface, leaving behind an oxygen vacancy, which is replenished from molecular oxygen in the ambient.

It is well documented in the literature that so called "monolayer"-type vanadia catalysts, i.e., catalysts with a vanadia loading corresponding to a monolayer or sub-monolayer surface coverage, are far more active than crystalline $\mathrm{V}_{2} \mathrm{O}_{5}$ nanoparticles [11]. In addition, the reactivity of supported vanadium oxides in oxidation reactions has been found to strongly depend on the support [7-10]. In particular, reducible oxides (e.g., ceria) have been shown to enhance the turnover frequency of this reaction as compared to nonreducible oxides like silica and alumina.

Monomeric $\mathrm{VO}_{4}$ entities have been suggested as one particularly important form of supported vanadia. Evidence for the presence of monomeric $\mathrm{VO}_{4}$ species on alumina has been found using x-ray absorption spectroscopy [12], although Raman, infrared, and ultravioletvisible spectroscopies are the most frequently used techniques for characterization of vanadia surface species (e.g., see [9, 13-18] and references therein). The nature of many absorption bands in the spectra is generally understood (e.g., vanadyl or $\mathrm{V}=\mathrm{O}$ ), but the precise determination of the 
fraction of isolated versus polymeric vanadate species is not trivial. Moreover, the atomic structure of the vanadia/support interface in the catalysts is not well established. For example, the frequency of the $\mathrm{V}=\mathrm{O}$ stretch in powdered catalysts varies between 1040 and $1010 \mathrm{~cm}^{-1}$ depending on the support and vanadia loading [7, 10, 19]. A band at $995 \mathrm{~cm}^{-1}$ has been reported for samples containing $\mathrm{V}_{2} \mathrm{O}_{5}$ crystallites [20]. In addition, a broad band at around $920 \mathrm{~cm}^{-1}$ seen in the Raman spectra at high vanadia loadings on alumina and titania supports has been attributed to polymeric (V-O-V) species [19]. Lee and Wachs found that this band was absent on silica-supported catalysts, while the $\mathrm{V}=\mathrm{O}$ stretch could be detected, which was interpreted as isolated $\mathrm{VO}_{4}$ units [15]. However, this statement has been revised by Magg et al. [21], who assigned the band at $\sim 920 \mathrm{~cm}^{-1}$ to vibrations involving interfacial $\mathrm{V}-\mathrm{O}-\mathrm{Al}(\mathrm{Si})$ bonds.

To elucidate the ODH reaction mechanism over vanadia on a molecular level, different model systems have been invoked that range from single crystals [22, 23] and thin films prepared on $\mathrm{TiO}_{2}$ [24-26], $\mathrm{W}(110)$ [27], $\mathrm{Au}(111)$ [27-31], $\mathrm{Rh}(111)$ [32-34], and $\mathrm{Cu}_{3} \mathrm{Au}(100)$ [35-37] to vanadia particles deposited onto oxide substrates [21, 38, 39] including ceria [40-42]. In addition to experimental investigations, density functional theory has been employed to explore the structural characteristics and reactivity towards methanol of model vanadia systems [43-48]. In particular, Shapovalov and Metiu have suggested that the structure of $\mathrm{VO}_{\mathrm{x}}$ on reducible oxides (i.e., titania and ceria) is strongly influenced by the position of oxygen atoms and metal cations on the surface [48].

It has been found that vanadyl terminated $\mathrm{V}_{2} \mathrm{O}_{5}(001)$ and $\mathrm{V}_{2} \mathrm{O}_{3}(001)$ films and single crystals are essentially inert toward methanol $[49,50]$. Depending on the preparation conditions, $\mathrm{V}_{2} \mathrm{O}_{3}(0001)$ and $\mathrm{V}_{2} \mathrm{O}_{5}(0001)$ films can be either $\mathrm{V}=\mathrm{O}$ or $\mathrm{V}$-terminated or both terminations may coexist. Recently, Romanyshyn et al. [39] showed that FA formation on $\mathrm{V}_{2} \mathrm{O}_{3}(0001)$ films in temperature programmed desorption (TPD) spectra of methanol was maximal when about half of the terminal $\mathrm{V}=\mathrm{O}$ had been removed by electron bombardment. The authors proposed that after the initial formation of $\mathrm{V}-\mathrm{OCH}_{3}$ and $\mathrm{V}-\mathrm{OH}$ from the $\mathrm{V}$ and $\mathrm{V}=\mathrm{O}$ sites, respectively, water would desorb due to the recombination of $2 \mathrm{~V}-\mathrm{OH}$ species, thus restoring one $\mathrm{V}=\mathrm{O}$, but also creating another $\mathrm{V}$ site. Recursive repetition would lead to the adsorption of twice as many methoxy groups as there were $\mathrm{V}=\mathrm{O}$ sites originally. If the original extent of reduction differs significantly from $50 \%$, then the overall FA formation would be less due to either less adsorption sites 
available for methoxy (original reduction $<50 \%$ ) or sub-stoichiometric abundance of $\mathrm{V}=\mathrm{O}$ as the proton acceptor (original reduction $>50 \%$ ).

A similar trend in reactivity towards FA was observed for supported vanadia clusters. Vanadia particles deposited on thin silica films, using water as a buffer layer, were $\mathrm{V}_{2} \mathrm{O}_{3}$ in nature and could be prepared either as $\mathrm{V}=\mathrm{O}$ and/or Vterminated [38]. The TPD spectra of methanol on these particles revealed essentially no FA production on the fully $\mathrm{V}=\mathrm{O}$ and $\mathrm{V}$ terminated surfaces, but FA production was observed on the partially reduced (or partially oxidized) surfaces [39].

There are several relevant model studies of methanol $\mathrm{ODH}$ on $\mathrm{TiO}_{2}(110)$-supported vanadia. Wong et al. found the pristine $\mathrm{TiO}_{2}(110)$ surface to be inert in this reaction, while the addition of one monolayer of vanadia activated the FA formation [51]. Addition of vanadia to form the multilayer caused the system to become inactive toward methanol ODH again. Also, Wang and Madix have studied the interaction of methanol with vanadia supported on a $\mathrm{TiO}_{2}$ (110) single crystal prepared by chemical vapor deposition of $\mathrm{H}_{2} \mathrm{O}$ and $\mathrm{VOCl}_{3}$ [52]. A more detailed study performed by Wong et al. addressed the oxidation state of vanadia deposits and how the oxidation state relates to the reactivity [53]. From methanol-pre-covered vanadia containing $\mathrm{V}^{3+}$, FA desorbed at $\sim 615 \mathrm{~K}$, while for the fully oxidized $\mathrm{V}^{5+}$ this temperature was significantly lower ( $485 \mathrm{~K})$.

Methanol oxidation on vanadia supported on both single crystal and polycrystalline ceria has previously been studied by the group of Vohs [41, 42]. They found that the FA desorption temperature resulting from methanol oxidation was highly dependent on the oxidation state of vanadium cations. For particles with a predominance of $\mathrm{V}^{+5}$ (e.g., in $\mathrm{V}_{2} \mathrm{O}_{5}$ ), the reaction limited FA desorption was observed at $\sim 540 \mathrm{~K}$, while for more reduced vanadia particles with a predominance of $\mathrm{V}^{+3}$ (e.g., in $\mathrm{V}_{2} \mathrm{O}_{3}$ ), the desorption occurred at $\sim 590 \mathrm{~K}$. Simulation of the TPD spectra suggested a desorption energy $\left(E_{\text {des }}\right)$ of $\sim 84.7$ and $\sim 158 \mathrm{~kJ} / \mathrm{mol}$ for half-monolayer films of $\mathrm{V}_{2} \mathrm{O}_{5}$ and $\mathrm{V}_{2} \mathrm{O}_{3}$, respectively (n.b., pre-exponential factors were $2 \times 10^{7} \mathrm{~s}^{-1}$ and $10^{13} \mathrm{~s}^{-1}$, respectively) [40]. The peak temperature for FA reaction-limited desorption from vanadia supported on polycrystalline ceria was found to vary between 525 and $610 \mathrm{~K}$, depending on sample pretreatments. Feng and Vohs have also investigated methanol adsorption on pure highsurface area, polycrystalline ceria and found FA desorption at 595 K [41]. Similarly, Mullins et al. found FA desorption from thin $\mathrm{CeO}_{2}(111)$ films at a slightly lower temperature in TPD 
spectra, $~ 570 \mathrm{~K}$ [54]. Interestingly, Mullins et al. found that FA desorption shifted to higher temperature $(\sim 640 \mathrm{~K})$ upon reduction of the ceria thin film [54].

In continuation of our previous work on vanadia based model catalysts (e.g., refs. [21, 23, $27,28,38,39,50]$ ), we aim to understand the role of ceria as a support in the ODH of methanol. We employ a well-defined model system, where vanadia is deposited onto $\mathrm{CeO}_{2}(111)$ thin films grown on $\mathrm{Ru}(0001)$. Recently, we have directly shown by scanning tunneling microscopy (STM) that vanadia forms small $\mathrm{V}=\mathrm{O}$ terminated species such as monomers, trimers, and oligomers at low loadings. The combined STM and infrared reflection absorption spectroscopy (IRAS) study, supported by DFT calculations, allowed us to establish a direct structure-spectroscopy relationship [55]. Furthermore, using the energies of hydrogenation and oxygen defect formation as descriptors for reactivity of oxidation catalysts, DFT calculations were shown to be consistent with the experimentally observed higher reactivity of vanadia/ceria systems towards methanol compared with that of vanadia and ceria surfaces [56].

In this paper, we present a detailed study of reactivity of methanol on vanadia/ceria surfaces by TPD and IRAS. The results reveal low temperature reactivity of vanadia species that was not previously observed for vanadia/silica or vanadia/alumina model systems. This reactivity is assigned to the presence of isolated vanadia species surrounded by a reduced ceria surface. It is concluded that the support effects reported in the literature for the real catalysts in ODH reactions are related to the stabilization of small vanadia $(+5)$ clusters by reducible oxide supports.

\section{Methods and Materials}

Experiments were performed in three separate ultrahigh vacuum (UHV) chambers with base pressures $\sim 5 \times 10^{10}$ mbar denoted IRAS, STM, and photoelectron spectroscopy (PES) in the following text. The IRAS chamber is equipped with an IR spectrometer (Bruker IFS 66/vs), a differentially pumped quadrupole mass spectrometer (QMS, HIDEN HAL RC 201), and a low energy electron diffraction/Auger electron spectroscopy system (LEED/AES, Specs). The STM chamber houses an STM (Omicron), an IR spectrometer (Bruker IFS 66/vs), and an PES with Scienta SES 200 analyzer. The PES chamber is located at the UE52-PGM beamline of the BESSY II synchrotron facility in Berlin and is equipped with LEED/AES and a Scienta SES 200 analyzer. 
Fully oxidized ceria films exhibiting a low number of point defects were grown on $\mathrm{Ru}(0001)$ single crystals as described elsewhere [57-59]. The $\mathrm{Ru}(0001)$ single crystal (from Mateck) was cleaned by repeated cycles of $\mathrm{Ar}^{+}$sputtering and annealing to $1300 \mathrm{~K}$. The temperature was controlled by a feedback control system (Schlichting Phys. Instrum.) with a type K thermocouple spot-welded to the edge of the crystal. Sample cleanliness was checked via low energy electron diffraction (LEED) and Auger electron spectroscopy (AES) and/or PES. Before deposition of cerium, the $\mathrm{Ru}(0001)$ sample was oxidized at $700 \mathrm{~K}$ for 5 minutes in an $\mathrm{O}_{2}$ background of $10^{-6}$ mbar such that a $(2 \times 2)-\mathrm{O}-\mathrm{Ru}(0001)$ pattern was visible by LEED. Ce was initially deposited in $10^{-6}$ mbar of $\mathrm{O}_{2}$ at $100 \mathrm{~K}$ in amounts approximately equivalent to form $\sim 3$ monolayers (ML) of $\mathrm{CeO}_{2}(111)$ on $\mathrm{Ru}(0001)$. Subsequently, the temperature was increased at a rate of $1 \mathrm{~K} / \mathrm{s}$ and kept at $700 \mathrm{~K}$ during deposition of the next $35 \mathrm{ML}$. After deposition, the sample was further oxidized for 15 minutes at $980 \mathrm{~K}$ in the same oxygen ambient (i.e., $10^{-6}$ mbar). The samples showed sharp diffraction spots in a $\operatorname{Ru}(0001)-(1.4 \times 1.4)$ LEED pattern characteristic for $\mathrm{CeO}_{2}$ (111) films [57]. The preparation of the films, showing large single crystal terraces, was very reproducible and was used in the IRAS and PES chambers that are not equipped with STM. A new ceria film was prepared for each vanadia/ceria sample studied.

Ce and V (both $99.99 \%$ from Goodfellow) were deposited using electron-beam-assisted evaporators (Focus EFM3). During evaporation the sample was biased at the same potential as the metal source (typically $\sim 600 \mathrm{~V}$ ) to prevent acceleration of metal ions toward the sample, which would create uncontrolled defects. Vanadium was deposited on ceria thin films cooled to $=150 \mathrm{~K}$ and then annealed to room temperature for 10 minutes in $10^{-6}$ mbar of $\mathrm{O}_{2}$. Annealing in oxygen was found to be particularly important since vanadium atoms apparently react with carbon containing species adsorbed from the background at low temperatures (e.g., $\mathrm{CO}_{2}$ ) to form products with a shifted $\mathrm{KO}$ stretching vibration $\left(980-990 \mathrm{~cm}^{-1}\right)$. Similar species have been observed in matrix isolation experiments [60]. In the IR and PES chambers the vanadium deposition rate was calibrated using a quartz microbalance, while STM was used in the STM chamber. This may cause small deviations in the absolute values for vanadia loading (a microbalance typically overestimates a coverage), but it does not affect the general trend observed in all three experimental setups. 
The PES spectrometer at BESSY was calibrated with a gold foil by setting the $\mathrm{Au} 4 \mathrm{f}_{7 / 2}$ level to $84.0 \mathrm{eV}$. PE spectra were obtained at grazing emission and a photon energy (hv) of 620 $\mathrm{eV}$ was used for most samples.

Methanol (Merck, $99.8 \%$, additionally purified by repeated freeze/pump/thaw cycles) was exposed to the sample using a directional gas doser. To ensure identical methanol coverage on the samples, ca. 5 Langmuirs $\left(1 \mathrm{~L}=10^{-6}\right.$ Torr sec) of methanol were dosed at room temperature. This procedure allowed FA production, which would have been obscured by a large, methanol multilayer peak, to be more clearly visible in TPD spectra. The fraction of signal intensity at $\mathrm{m} / \mathrm{z}=29$ (the major ionization fragment of FA) resulting from methanol cracking in our QMS was found to be 1.4 and was determined using multilayer desorption of methanol where no reactivity and/or interaction with the substrate is expected. To obtain the pure FA desorption signal, the 29 amu signal was subtracted according to $\mathrm{I}^{\mathrm{FA}}=\mathrm{I}^{\mathrm{m} / \mathrm{z}=29}-1.4 \times \mathrm{I}^{\mathrm{m} / \mathrm{z}=31}$. While this subtraction accounts for the specific cracking pattern of methanol in our mass spectrometer, it does not take into consideration other effects that may be temperature sensitive (e.g., reaction on the walls of the shielding cone of the differentially pumped QMS or changes in the effective pumping speed with changing pressure within the shielding cone).

\section{Results and Discussion}

\subsection{Structural characterization of vanadia supported on $\mathrm{CeO}_{2}(111)$}

The morphology of the $\mathrm{VO}_{\mathrm{x}} / \mathrm{CeO}_{2}(111)$ model system was initially characterized using STM. The pristine ceria films exhibit a low number of point defects (typically assigned to $\mathrm{O}$ vacancies) as previously shown by gold decoration [58,59]. STM images of vanadia/ceria surfaces as a function of vanadia coverage are shown in Fig. 1. In Fig. 1a wide terraces separated by monatomic, $3 \AA$ Ahigh steps of $\mathrm{CeO}_{2}(111)$ are covered by small protruding spots of highly dispersed and randomly distributed species. The absence of preferential nucleation sites indicates the strong interaction of $\mathrm{V}$ atoms with the $\mathrm{CeO}_{2}$ surface (c.f., Au that primarily forms nanoparticles at step edges [58]). The apparent size of these species measured by STM, $3 \AA$ in diameter and $\sim 1 \AA$ in height (depending on the bias), points to these being monomeric vanadia in nature. With increasing vanadia coverage up to $0.7 \mathrm{~V} / \mathrm{nm}^{2}$, the density of monomeric species 
increases, which may agglomerate to form dimers and flat trimers, as shown in Fig. 1b. Further increases in the vanadia coverage result in ill-defined large aggregates with a relatively broad size distribution, indicating kinetically limited growth of the vanadia particles. However, it is clear that the majority of vanadia deposits are two-dimensional in nature (see Fig. 1c).

Upon heating to $700 \mathrm{~K}$ in an oxygen ambient the monomers sinter. At a coverage of 0.7 $\mathrm{V} / \mathrm{nm}^{2}$, trimers are observed in abundance on the ceria surface (see Fig. 1e). At higher coverages, trimers and hexagonally shaped heptamers dominate the surface. Apparently, the particle size distribution becomes narrower upon annealing (c.f., Fig. 1e and 1f). These two-dimensional islands exhibit a lateral distance of $3.7 \pm 0.2 \AA$ between the protrusions, that matches the lattice constant of the underlying $\mathrm{CeO}_{2}(111)$ surface $(3.83 \AA$ ) well, and an apparent height of $1.3 \pm 0.3$ $\AA$, (i.e. about the same as for monomers). These findings suggest that $\mathrm{V}=\mathrm{O}$ groups in monomers, trimers, and oligomers occupy the same sites with respect to the ceria substrate.

Such morphology, where vanadia wets the ceria surface, is different from that previously observed for vanadia supported on alumina and silica films [38, 62, 63], where primarily threedimensional nanoparticles were formed from the onset. This comparison again highlights the strong interaction of vanadia with ceria. At intermediate coverages, various vanadia aggregates that ranged from dimers to twodimensional islands were imaged by STM (see Fig. 1 and also discussion in [55]). However, all these structures occurring at higher vanadia coverage will be referred to as polymeric vanadia species.

The electronic structure of vanadia deposits was studied by PES using synchrotron light. Spectra for the $\mathrm{V} 2 \mathrm{p}_{3 / 2}$ core level of $\mathrm{VO}_{\mathrm{x}} / \mathrm{CeO}_{2}$ under various conditions are shown in Fig. 2 . The spectra at two vanadia loadings ( $\sim 2$ and $\sim 6 \mathrm{~V} / \mathrm{nm}^{2}$ ) are dominated by a peak at $\sim 517 \mathrm{eV}$, which is characteristic for $\mathrm{V}$ in the highest, +5 oxidation state (see Fig. $2 \mathrm{a}$ ). This binding energy agrees well with results previously obtained for a $\mathrm{V}_{2} \mathrm{O}_{5}(001)$ film grown on a $\mathrm{Au}(111)$ crystal [64]. Concomitantly, it has been shown that $\mathrm{Ce}$ is reduced in agreement with previous results $[55,65$, 66]. As the coverage of vanadia on ceria increases, an additional broad signal centered at $\sim 515.7$ $\mathrm{eV}$ appears. This binding energy is characteristic of a lower, +3 oxidation state as found in $\mathrm{V}_{2} \mathrm{O}_{3}(0001)$ films $[27,28]$ and vanadia nanoparticles formed on alumina and silica films, which have an overall tendency for a $\mathrm{V}_{2} \mathrm{O}_{3}$ sesquioxide-like stoichiometry at the low oxygen pressures used during preparation [62, 63]. Wong and Vohs [65] also have observed V with a binding energy of 515.7 for higher vanadia coverages (i.e., 0.25-5.5 $\mathrm{ML}$ or 5-100 $\mathrm{V} / \mathrm{nm}^{2}$ ) on $\mathrm{CeO}_{2}(111)$. 
Infrared spectra highlighting the vanadyl $(\mathrm{V}=\mathrm{O})$ stretching region of vanadia/ceria samples used for methanol adsorption studies are shown in Fig. 3a. In these experiments vanadia coverages ranged from 1.0 to $5.5 \mathrm{~V} / \mathrm{nm}^{2}$, as measured by a microbalance. The IRA spectra in Fig. 3a are referenced to the spectrum of the "as-prepared" ceria film. At the lowest coverage of vanadia $\left(1.0 \mathrm{~V} / \mathrm{nm}^{2}\right)$, a relatively sharp peak at $1008 \mathrm{~cm}^{-1}$ is observed. As the coverage increases to $2.7 \mathrm{~V} / \mathrm{nm}^{2}$, an additional peak with low intensity appears at $1036 \mathrm{~cm}^{-1}$; this peak dominates the spectra at the highest coverage (i.e., $5.5 \mathrm{~V} / \mathrm{nm}^{2}$ ).

Previously, a frequency assignment to monomeric and polymeric vanadia species was based on comparison to powdered vanadia halogen compounds (i.e., $\operatorname{VOX}_{3}$ where $\mathrm{X}=\mathrm{F}, \mathrm{Cl}, \mathrm{Br}$ ) and on assumptions about the relationship between vanadia loading and particle size (e.g, see [13] and references therein). In particular, monomeric vanadia species supported on ceria powder catalysts were assigned to a higher Raman frequency $\left(1034 \mathrm{~cm}^{-1}\right)$ while polymeric vanadia/ceria were assigned to a lower Raman frequency $\left(1017 \mathrm{~cm}^{-1}\right)$ [8, 18]. However, our recent study [55] has directly established the relationship between the nuclearity of vanadia species and the IRA frequencies. The monomeric species on $\mathrm{CeO}_{2}$ consist of $\mathrm{V}$ bonded to three $\mathrm{O}$ surface atoms of the support, and the apex $\mathrm{O}$ atom is double-bonded to $\mathrm{V}$ as a vanadyl group resulting in the 5+ oxidation state. As the coverage of vanadia increases, polymerization of the $\mathrm{VO}_{4}$ entities into the trimers and larger oligomers occurs, which is accompanied by a blue-shift in the IRA spectra. The shift to higher frequencies with increasing vanadia cluster size is assigned to the increasing extent of dipole coupling. The latter probably dominates for alumina- [62] and silica-supported $[38,67]$ vanadia nanoparticles, which show an IRAS band at $\sim 1040 \mathrm{~cm}^{-1}$. (N.b., Recent force field calculations suggest that this blue-shifted vibrational band may have contributions not only from the $\mathrm{V}=\mathrm{O}$ stretch but also from a $\mathrm{V}-\mathrm{O}-\mathrm{Si}(\mathrm{Al})$ bending mode [68].) Similarly, $\mathrm{V}=\mathrm{O}$ terminated $\mathrm{V}_{2} \mathrm{O}_{3}(0001)$ and $\mathrm{V}_{2} \mathrm{O}_{5}(001)$ surfaces also exhibit higher vanadyl frequencies (i.e., around $1040 \mathrm{~cm}^{-1}$ ) [27-29].

\subsection{Methanol adsorption on vanadia/ceria}

Fig. 4 shows STM images of $\sim 0.3 \mathrm{~V} / \mathrm{nm}^{2}$ on ceria before (a) and after (b) dosing methanol and annealing to $450 \mathrm{~K}$. A few vanadia monomers with a dark "halo" feature can be observed as highlighted by the arrow in Fig. 4a. While the origin of these minority species is unknown, we speculate that they may be due either to reduction of the ceria film in the area 
immediately surrounding the monomer or to interaction of $\mathrm{V}$ adatoms with the point defects of ceria. Fig. $4 \mathrm{~b}$ illustrates that even in the presence of methanol, vanadia monomers begin to sinter forming dimers and trimers at $\mathrm{T}_{\mathrm{s}}=450 \mathrm{~K}$.

Fig. 3b,c shows IRA spectra after dosing $\sim 5 \mathrm{~L}$ of methanol at room temperature. The spectra are referenced to the pristine $\mathrm{CeO}_{2}$ film in Fig. 3b, while in Fig. 3c the spectra are referenced to the corresponding $\mathrm{VO}_{\mathrm{x}} / \mathrm{CeO}_{2}$ pre-adsorption spectra shown in Fig. 3a. For methanol adsorption on a pristine $\mathrm{CeO}_{2}$ film, also shown in Fig. 3b, two peaks are observed in the C-O stretching region, one at $1104 \mathrm{~cm}^{-1}$ and another at $1080 \mathrm{~cm}^{-1}$. (Analysis of the C-H stretch region in the IRA spectra, more clearly resolved using $\mathrm{CD}_{3} \mathrm{OD}$, suggests that these $\mathrm{C}-\mathrm{O}$ stretches correspond to methoxy $\left(\mathrm{CH}_{3} \mathrm{O}-\right)$ on ceria; see also discussion in ref. [69]). For the two lowest coverages of $\mathrm{VO}_{\mathrm{x}}$ on $\mathrm{CeO}_{2}$, there are no clearly resolvable peaks in these spectra to distinguish between methanol and methoxy adsorption. However, the absence of the vanadyl vibrational feature suggests that methanol strongly interacts with vanadia. For methanol adsorption on the $5.5 \mathrm{~V} / \mathrm{nm}^{2}$ sample, a somewhat broad peak is apparent at $1031 \mathrm{~cm}^{-1}$ with an integrated intensity that is approximately half the integrated intensity of the $1036 \mathrm{~cm}^{-1}$ vanadyl peak observed for the same coverage in Fig. 3a. Based on $\mathrm{C}-\mathrm{H}$ stretching vibrations observed in the IR spectrum (not shown) and comparison to similar IR spectra for methanol adsorption on partially reduced $\mathrm{V}_{2} \mathrm{O}_{3}(001)$ thin films [64], this peak is assigned to the C-O stretch of methoxy bound to vanadia, although there also may be a contribution to the peak intensity from vanadyl groups that remain on the surface and have only slightly differing frequencies (see Fig. 3a).

The spectra in Fig. 3c more clearly illustrate the structural changes that occur as a result of methanol adsorption on the vanadia/ceria surface. Here, upward peaks (i.e., negative absorbance or positive transmittance) occur at the same vanadyl frequencies observed in Fig. 3a (i.e., 1008 and $1036 \mathrm{~cm}^{-1}$ ). For all coverages of vanadia on ceria, the integrated intensity of the peaks in Figs. 3a and 3c are approximately equa l. The upward intensity of the vanadyl stretching vibration observed in Fig. 3c points to either consumption of the vanadyl species (e.g., weakening or breaking the $\mathrm{V}=\mathrm{O}$ bond) or a geometric change such that the vibration becomes IR inactive by the surface dipole selection rule (e.g., tilting of the $\mathrm{V}=\mathrm{O}$ bond). (For a discussion of IR intensity based on surface selection rules refer to refs. [70, 71]).

PES spectra shown in Fig. $2 b$ indicate that consumption of the vanadyl species rather than a geometric effect explains the depletion of IR intensity. The $6.0 \mathrm{~V} / \mathrm{nm}^{2}$ sample was first 
pre-annealed in $\mathrm{O}_{2}$ to fully oxidize $\mathrm{V}$ atoms to $\mathrm{a}+5$ oxidation state. After dosing methanol at low temperature and annealing to $300 \mathrm{~K}$, the intensity at $517.0 \mathrm{eV}$ (i.e., $\mathrm{V}^{5+}$ ) decreased while the intensity at $515.7 \mathrm{eV}$ increased. Presumably, the changing intensity reflects reduction of $\mathrm{V}$ atoms. The PE spectra indicate that the vanadyl groups are directly interacting with the incident methanol, accepting either the alcohol proton, the methoxy intermediate, or both.

\subsection{Methanol reactivity on vanadia/ceria}

TPD spectra of the major desorption products after methanol exposure at $300 \mathrm{~K}$, methanol and formaldehyde (with a subtraction of the methanol cracking pattern in our QMS, as discussed in Methods and Materials), are presented as a function of vanadia coverage in Fig. 5. Masses corresponding to $\mathrm{H}_{2}, \mathrm{CH}_{4}, \mathrm{H}_{2} \mathrm{O}, \mathrm{CO}$, and $\mathrm{CO}_{2}$ were also monitored during TPD experiments, but did not provide compelling information about the system and have been omitted here for brevity. Features appearing below $300 \mathrm{~K}$ are assigned to a combination of methanol desorption after readsorption from the background upon cooling to $100 \mathrm{~K}$ for the IRAS and TPD measurements plus recombinative desorption of methanol from surface-bound hydroxyl and methoxy groups.

The pristine $\mathrm{CeO}_{2}$ (111) film shows a reaction limited FA desorption signal at $\sim 565 \mathrm{~K}(\gamma$ peak, see also $[41,54])$. In the presence of vanadia, the $\gamma$ desorption peak shifts by $25 \mathrm{~K}$ to $\sim 590$ $\mathrm{K}$. As the coverage of vanadia increases, the integral intensity of the $\gamma$ peak decreases and finally becomes negligible for the highest $\mathrm{VO}_{\mathrm{x}}$ coverage of $5.5 \mathrm{~V} / \mathrm{nm}^{2}$. Two peaks related to the interaction of methanol with the vanadia/ceria surfaces appear at lower temperatures. From lowest to highest desorption temperature, these peaks are labeled $\alpha(\sim 370 \mathrm{~K})$ ?and $\beta(475$ ? 505 $\mathrm{K})$. Although both the $\alpha$ and $\beta$ peaks appear at low and intermediate coverages of vanadia (refer to Fig. $5 \mathrm{~b}$ and c), their integral intensities have contrasting behavior as a function of coverage. As the coverage of vanadia increases from 1.0 to $2.7 \mathrm{~V} / \mathrm{nm}^{2}$, the area of the $\alpha$ peak increases, while the area of the $\beta$ peak decreases. For the highest coverage of vanadia, only the $\beta$ peak is observed in the TPD spectrum (see Fig. 5d). It is shifted to higher temperature, and the integrated intensity remains approximately constant as the coverage increases from 2.7 to $5.5 \mathrm{~V} / \mathrm{nm}^{2}$.

The desorption energies $\left(E_{\text {des }}\right)$ corresponding to the TPD peaks shown in Fig. 5 were calculated according to the Redhead formula [72]. Although this analysis is only valid for first 
order desorption, we have employed it here to give a rough approximation of the desorption energy for each TPD peak. Using a heating rate of $\mathrm{dT} / \mathrm{dt}=3 \mathrm{~K} / \mathrm{s}$ and a frequency factor of $v=$ $10^{13} \mathrm{~s}^{-1}$, the desorption energies corresponding to the $\alpha, \beta$, and $\gamma$ peaks are 96,125 ? 133 , and 149? $156 \mathrm{~kJ} / \mathrm{mol}$, respectively. Assuming the same frequency factor (i.e., $10^{13} \mathrm{~s}^{-1}$ ) and applying the Redhead analysis to other relevant systems in the literature provides a more even-handed method for comparing to our system.

Mullins and coworkers [54] have reported a TPD peak at $\sim 570 \mathrm{~K}\left(\mathrm{E}_{\mathrm{des}} \sim 150 \mathrm{~kJ} / \mathrm{mol}\right)$ for formaldehyde resulting from $\mathrm{CH}_{3} \mathrm{OH}$ adsorption on $\mathrm{CeO}_{2}(111)$ thin films, in close agreement with the $\gamma$ peak reported here. They also observed that for reduced ceria thin films of average stoichiometry $\mathrm{CeO}_{1.8}$ the FA desorption temperature shifted to greater than $600 \mathrm{~K}\left(\mathrm{E}_{\mathrm{des}}>159\right.$ $\mathrm{kJ} / \mathrm{mol}$ ). Note that in our experiments methanol was exposed to the sample at $300 \mathrm{~K}$ (i.e., far above the desorption temperature of water that reduces the ceria surface). Indeed, PES measurements of the ceria valence band in our samples showed an increase of the Ce4f signal upon vanadia deposition $[42,55,66]$ as well as methanol adsorption (data not shown, see also [73] for pure ceria films). Thus, the shift observed by Mullins et al. [54] for ceria films and by us for the $\gamma$ peak on vanadia/ceria most likely have the same origin (i.e., reduction of the ceria film). Thus, the PES data in combination with the TPD spectra present strong evidence for a reduced ceria film. This is an important point in identifying the most plausible reaction mechanism for methoxy formation on $\mathrm{VO}_{\mathrm{x}} / \mathrm{CeO}_{2}$.

Desorption temperatures for FA produced on partially reduced vanadia thin films and particles vary between 510 and $590 \mathrm{~K}\left(\mathrm{E}_{\mathrm{des}} \sim 142-158 \mathrm{~kJ} / \mathrm{mol}\right)$, depending on the level of reduction $[39,40,50]$. These values are higher than the $\alpha$ and $\beta$ peaks presented here. Fully oxidized, $\mathrm{V}=\mathrm{O}$ terminated $\mathrm{V}_{2} \mathrm{O}_{3}(0001)$ and $\mathrm{V}_{2} \mathrm{O}_{5}(001)$ thin films have been found to be inert with respect to methanol oxidation $[39,49,50]$. However, fully reduced $\mathrm{V}_{2} \mathrm{O}_{5}$ films were found to have a peak desorption temperature of about $450 \mathrm{~K}\left(\mathrm{E}_{\mathrm{des}} \sim 125 \mathrm{~kJ} / \mathrm{mol}\right)$ [49], which is in relative agreement with the $\beta$ peak for lower vanadia coverages (refer to Fig. $5 b$ and c).

Fig. 5 shows that the $\alpha$ peak is only observed at low and intermediate vanadia coverages where monomeric vanadia species have been identified by IRAS (see Fig. 3a). However, during the TPD experiments, sintering of monomeric species to form polymeric vanadia may occur as mentioned in Section 3.1 and illustrated in Fig. 4b. This speculation is supported by the fact that the alpha peak was not observed during subsequent TPD runs performed with the same model 
catalyst (data not shown). Thus, it is likely that polymeric vanadia species form during the temperature ramp of the TPD experiments, thus resulting in FA desorption as the $\beta$ peak. At intermediate coverage, the initial density of monomeric species is higher, but some polymeric species are already present and sintering causes these particles to form even larger vanadia aggregates which expose fewer reactive (presumably interfacial) sites. This would result in an increase of the $\alpha$ peak reactivity, but a decrease of the $\beta$ peak reactivity, as observed in Fig. 5b,c. For the highest coverage of vanadia where large polymeric species dominate the surface structure prior to the temperature ramp, the $\beta$ peak is shifted substantially (by about $30 \mathrm{~K}$ ), and the overall reactivity diminishes.

In order to eliminate the effects of structural changes during TPD acquisition, $1 \mathrm{~V} / \mathrm{nm}^{2}$ samples were pre-annealed to $700 \mathrm{~K}$ in $\mathrm{O}_{2}$ prior to methanol adsorption at $300 \mathrm{~K}$. This treatment results in sintering of vanadia species as evidenced by a frequency shift from 1008 to $1034 \mathrm{~cm}^{-1}$ (see Fig. 6a), although panel (b) shows that some vanadia monomers can still be present, which are most likely stabilized by a higher density of surface defects in this sample. In both cases, the respective TPD spectra (see Figs. $6 \mathrm{c}, \mathrm{d}$ ) did not reveal the $\alpha$ peak. Moreover, the $\beta$ peak shifted toward higher temperatures as compared to the spectrum for the non-annealed sample at the same vanadia coverage, thus resembling the spectrum for high coverage (i.e. $5.5 \mathrm{~V} / \mathrm{nm}^{2}$ ) prepared at $300 \mathrm{~K}$ (see Fig. 5d). In addition, the absolute intensity of the $\beta$ peak decreased by a factor of $\sim 2$ as compared to a sample at the same vanadia loading (i.e., $1 \mathrm{~V} / \mathrm{nm}^{2}$ ) but prepared at $300 \mathrm{~K}$ (Fig. 5b). Both findings are consistent with the formation of larger vanadia aggregates upon high-temperature annealing ultimately resulting in high temperature reactivity at $\sim 500 \mathrm{~K}$.

These experiments suggest that monomeric $\mathrm{V}=\mathrm{O}$ species are necessary for the low temperature reactivity to occur. On the other hand, the corresponding IR spectra shown in Figs. $6 a, b$ revealed that the vanadyls on the annealed surfaces are stable towards methanol adsorption, i.e. in contrast to the case when vanadia species were prepared at $300 \mathrm{~K}$ (see Fig. 3).

\subsection{Proposed reaction mechanisms}

Following the experimental results discussed in the previous sections, we are now in a position to rationalize the key observations of methanol reaction with vanadia/ceria surfaces. The combined IRAS and TPD measurements clearly show that methanol reactivity by ceria- 
supported vanadia is drectly related to the surface structure of the catalyst. At high vanadia coverage (i.e., $5.5 \mathrm{~V} / \mathrm{nm}^{2}$ ), where little of the ceria film is exposed, the reaction mechanism appears to be similar to the selective oxidation of methanol to formaldehyde on vanadia thin films [39, 61]. This reaction mechanism is expressed in Scheme 1 (adapted from [39]). For partially reduced $\mathrm{V}_{2} \mathrm{O}_{3}$ films, experimental measurements and theoretical calculations support a mechanism in which the alcohol proton is removed by an acid-base reaction, in which a vanadyl oxygen accepts the proton and an adjacent bare vanadium atom serves as the binding site for methoxy. Thus, $\mathrm{V}-\mathrm{OH}$ and $\mathrm{V}-\mathrm{OCH}_{3}$ groups populate the surface. At sufficiently high surface temperature (>250 K), the hydroxyl groups may diffuse and combine to form water, which desorbs into the gas phase leaving behind a bare vanadium atom. Alternatively, the hydroxyl groups may also recombine with methoxy and desorb from the surface as methanol. Upon heating above room temperature, $\mathrm{H}$ from the methyl group of methoxy is abstracted either by vanadyl oxygen or surface oxygen in the ceria film in an oxidation-reduction (redox) reaction. Thus, methoxy is oxidized to form formaldehyde, while $\mathrm{V}$ and/or Ce are reduced. Once again, hydroxyl groups on the surface may diffuse, recombine, and desorb as water. This second hydrogen abstraction is generally considered the rate-limiting step with prompt desorption of FA upon formation. The proposed mechanism requires that vanadyl groups are adjacent to bare vanadium atoms for the initial proton transfer to occur, creating hydroxyl and methoxy groups that can react further. The lack of initial binding sites for methoxy on fully vanadyl-terminated vanadia films would explain why they are unreactive toward methanol oxidation. Additionally, methanol ODH experiments using ${ }^{18} \mathrm{O}$-labeled vanadia films showed incorporation of isotopically labeled oxygen into FA [39]. This would suggest that the reaction mechanism for the redox step involves oxygen exchange between the vanadia film and methoxy groups, possibly through a dioxomethylene $\left(\mathrm{CH}_{2} \mathrm{O}_{2}\right)$ reactive intermediate as proposed in [39]. Since no appreciable $\mathrm{CH}_{4}$ was observed in our TPD spectra, it appears that the reaction expressed in Eq. 3 of Scheme 1 does not occur for vanadia/ceria under the conditions studied here.

\section{Scheme 1}

$$
\begin{aligned}
& \mathrm{CH}_{3} \mathrm{OH}+\mathrm{V}_{\text {(surf) }}+\mathrm{O}_{\text {(surf) }} ? \mathrm{CH}_{3} \mathrm{OV} \text { (surf) }+\mathrm{HO}_{\text {(surf) }} \\
& \mathrm{CH}_{3} \mathrm{OV}_{\text {(surf) }}+\mathrm{O}_{\text {(surf) }} ? \quad \mathrm{CH}_{2} \mathrm{O}_{2}(?) \quad ? \quad \mathrm{CH}_{2} \mathrm{O} ?+\mathrm{HO}_{\text {(surf) }}+\mathrm{V}_{\text {(surf) }} \\
& \mathrm{CH}_{3} \mathrm{OV}_{\text {(surf) }}+\mathrm{HO}_{\text {(surf) }} ? \quad \mathrm{CH}_{4} ?+\mathrm{HO}_{\text {(surf) }}+\mathrm{V}_{\text {(surf) }}
\end{aligned}
$$


The reaction mechanism considered for vanadia thin films seems likely to dominate methanol reactivity for high vanadia coverages on ceria. IR spectra for the adsorption of methanol on $\mathrm{V}_{2} \mathrm{O}_{3}(0001)$ [39] are very similar to the spectra shown in Fig. 3c (e.g., a similar depletion of the IR intensity for the $\mathrm{V}=\mathrm{O}$ stretch and appearance of the $\mathrm{CO}$ stretch in methoxy were observed). Moreover, the desorption spectra of FA from $5.5 \mathrm{~V} / \mathrm{nm}^{2}$ on ceria and for vanadia thin films have similar peak temperatures and desorption energies $\left(c . f . \mathrm{T}_{\mathrm{p}} \sim 505 \mathrm{~K}\right.$ and $\mathrm{E}_{\mathrm{des}}=133$ $\mathrm{kJ} / \mathrm{mol}$ for the $\beta$ peak, and $\mathrm{T}_{\mathrm{p}} \sim 450-510 \mathrm{~K}$ and $\mathrm{E}_{\text {des }}=125-142 \mathrm{~kJ} / \mathrm{mol}$ for reduced $\mathrm{V}_{2} \mathrm{O}_{5}$ thin films [61]). Thus, it seems that the same reaction mechanism determined for methanol ODH on reduced vanadia thin films, also applies to large vanadia particles on ceria thin films. In this case, depletion of the vanadyl IR signal is due to vanadyl oxygen consumption via the formation of a hydroxyl group (i.e., $\mathrm{V}_{\text {(surf) }}=\mathrm{O}$ becomes $\mathrm{V}_{\text {(surf) }} \mathrm{OH}$ ) and subsequent water desorption (i.e., $2 \mathrm{~V}_{\text {(surf)- }}$ $\mathrm{OH}$ yield $\mathrm{V}_{\text {(surf) }}, \mathrm{V}_{\text {(surf) }}=\mathrm{O}$, and $\mathrm{H}_{2} \mathrm{O}$ ?). This process is accompanied by vanadia reduction as detected by PES (see Fig. 2b).

At lower vanadia coverages (i.e., 1.0 and $2.7 \mathrm{~V} / \mathrm{nm}^{2}$ ), vanadia is expected to be highly dispersed, existing as monomers, trimers, and small oligomers [55] surrounded by extensive regions of the ceria film. The desorption energy/reaction barrier for FA is lower as compared to either pure vanadia or pure ceria surfaces. Thus, an alternative mechanism involving both vanadia species and the ceria film or the interfacial region between these metal oxides seems most likely. Many possibilities can be envisioned; some are depicted in Scheme 2, where only a vanadyl monomer is shown for simplicity. One possibility is that the alcohol proton is transferred to the vanadyl group, forming a $\mathrm{V}-\mathrm{OH}$, and methoxy binds to the ceria support (structure I). Alternatively, the alcohol proton could bind to oxygen in ceria, breaking one of the interfacial V$\mathrm{O}$ bonds. This would result in the formation of a hydroxyl on the ceria support and a vanadyt methoxy complex (i.e., $\mathrm{O}=\mathrm{V}-\mathrm{OCH}_{3}$ ), as previously suggested by DFT studies of methanol ODH on vanadia monomers supported by $\mathrm{SiO}_{2}$ or $\mathrm{TiO}_{2}[39,7476]$ (structure II). Another possibility is that isolated vanadyl species are not as sterically hindered as vanadyl groups in vanadia thin films, and both the hydroxyl and the methoxy are bound to the vanadia forming a $\mathrm{HO}-\mathrm{V}-\mathrm{OCH}_{3}$ species (structure III). 


\section{Scheme 2}
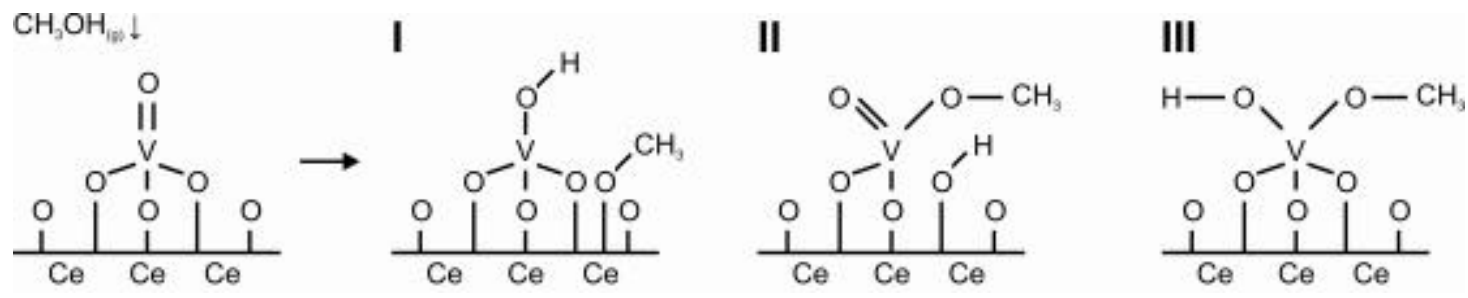

Of the options, structure I of Scheme 2 agrees best with the key experimental findings observed in this study, i.e., depletion of the $\mathrm{V}=\mathrm{O}$ band, $\mathrm{V}$ reduction upon methanol adsorption, and available, reduced $\mathrm{Ce}$ sites in close proximity to $\mathrm{V}=\mathrm{O}$ serving as binding sites for methoxy. Although we cannot know the exact location of the reduced Ce sites on our model catalyst, TPD and PES spectra show that the film does have these reduced sites and we assume that some will be in close proximity to vanadia species. The viability of this reaction is reflected by effects of methanol adsorption on the $\mathrm{V}=\mathrm{O}$ band, which depends on the oxidation temperature (c.f., $300 \mathrm{~K}$ vs $700 \mathrm{~K}$ in Figs. 5 and 6). IRA-spectra of Fig. 6 reveal that the vanadyl species formed after oxidation at $700 \mathrm{~K}$ are not consumed upon adsorption of methanol, i.e. in contrast to the vanadia/ceria surface formed by oxidation at $300 \mathrm{~K}$ (see Fig. 3). It seems plausible that oxidation at $700 \mathrm{~K}$ not only causes sintering of vanadia species but also modifies the Ce surface surrounding vanadyls such that it cannot accommodate methoxy species. Therefore, the low temperature reactivity observed here for vanadia/ceria seems to be related both to high dispersion of vanadia and to the degree of reduction of the ceria support close to $V=O$ species.

Finally, the TPD spectra in Fig. 5 show that FA desorption is always accompanied by some desorption of methanol at the same temperature. This might imply that a disproportionation reaction is also occuring, whereby two methoxy species give rise to one methanol and one formaldehyde molecule, both desorbing upon formation. Interestingly, the ratio of methanol and FA desorption signals decreases with the temperature and is the highest for the $\alpha$ state at all vanadia coverages where $\alpha$ is observed. Therefore, a disproportionation pathway to the overall FA production seems most prevalent at low temperatures.

Although the experimental evidence strongly suggests a specific reaction mechanism for the acid-base reaction responsible for removing the alcohol proton from methanol, detailed theoretical studies are necessary to elucidate the complete reaction mechanism, in particular the oxidation-reduction step in which a methyl proton is abstracted. 


\section{Summary}

The combined STM, IRAS and PES studies of model $\mathrm{VO}_{\mathrm{x}} / \mathrm{CeO}_{2}(111)$ catalysts of different coverage presented here showed formation of isolated monomeric species and two dimensional vanadia islands that wet the ceria support as previously assumed for the real "monolayer"-type catalysts. The vanadia species exhibit $\mathrm{V}$ in $\mathrm{a}+5$ oxidation state and expose vanadyl $(\mathrm{V}=\mathrm{O})$ groups with stretching frequencies that blue-shift from $\sim 1008 \mathrm{~cm}^{-1}$ to $\sim 1040 \mathrm{~cm}^{-1}$ at increasing vanadia coverage.

TPD studies of methanol on vanadia/ceria at different vanadia coverage revealed two regimes, in addition to formaldehyde production on the bare ceria surface that occurs at 570-590 $\mathrm{K}$, that are believed to each correlate with a specific vanadia structure on ceria. The polymeric vanadia species give rise to FA formation at temperatures similar to those previously observed for vanadia thin films and alumina and silica supported vanadia nano-particles ( $500 \mathrm{~K})$. A low temperature reactivity (at $\sim 370 \mathrm{~K}$ ), observed at low vanadia coverages, is assigned to the reactivity of monomeric $\mathrm{V}=\mathrm{O}$ species surrounded by a reduced ceria surface. It appears that the support effects reported in the literature for the real vanadia catalysts are related to the stabilization of small and isolated vanadia species by reducible oxide supports.

\section{Acknowledgements}

We acknowledge support from the Deutsche Forschungsgemeinschaft (DFG) through SFB546 ("Structure and reactivity of transition metal oxides") and the Cluster of Excellence "Unifying concepts in catalysis" (UNICAT), coordinated by the TU Berlin, and the Fonds der Chemischen Industrie. H.L.A. and D.S. gratefully acknowledge fellowship support by the Alexander von Humboldt Foundation. The authors would also like to acknowledge Dr. Helmut Kuhlenbeck, Dr. Marko Sturm, and Mr. Matthias Naschitzki technical assistance at BESSY II. 


\section{References.}

[1] M. Cozzolino, R. Tesser, M. Di Serio, P. D'Onofrio and E. Santacesaria, Catal. Today, 128 (2007) 191.

[2] G. Reuss, W. Disteldorf, W. Grundler and A. Hilt, Ullmann's Encyclopedia of Industrial Chemistry, Wiley VCH, 2002.

[3] A.P.V. Soares and M.F. Portela, Catalysis Reviews-Science and Engineering, 47 (2005) 125.

[4] G. Deo, I.E. Wachs and J. Haber, Critical Reviews in Surface Chemistry, 4 (1994) 141.

[5] A. Khodakov, B. Olthof, A.T. Bell and E. Iglesia, J. Catal., 181 (1999) 205.

[6] M.V. Martinez-Huerta, G. Deo, J.L.G. Fierro and M.A. Bañares, J. Phys. Chem. C, 112 (2008) 11441.

[7] B. Olthof, A. Khodakov, A.T. Bell and E. Iglesia, J. Phys. Chem. B, 104 (2000) 1516.

[8] M.A. Bañares, M.V. Martinez-Huerta, X.T. Gao, I.E. Wachs and J.L.G. Fierro, in A. Corma, F.V. Melo, S. Mendioroz and J.L.G. Fierro (Editors), Stud. Surf. Sci. Catal., Vol. 130D, Elsevier, Amsterdam, 2000, p. 3125.

[9] B.M. Weckhuysen and D.E. Keller, Catal. Today, 78 (2003) 25.

[10] I.E. Wachs, Catal. Today, 100 (2005) 79.

[11] T. Kim and I.E. Wachs, J. Catal., 255 (2008) 197.

[12] M. Ruitenbeek, A.J. van Dillen, F.M.F. de Groot, I.E. Wachs, J.W. Geus and D.C. Koningsberger, Top. Catal., 10 (2000) 241.

[13] G.T. Went, S.T. Oyama and A.T. Bell, J. Phys. Chem., 94 (1990) 4240.

[14] S.C. Su and A.T. Bell, J. Phys. Chem. B, 102 (1998) 7000.

[15] E.L. Lee and I.E. Wachs, J. Phys. Chem. C, 112 (2008) 6487.

[16] H.S. Kim, S.A. Zygmunt, P.C. Stair, P. Zapol and L.A. Curtiss, J. Phys. Chem. C, 113 (2009) 8836.

[17] B. Kilos, A.T. Bell and E. Iglesia, J. Phys. Chem. C, 113 (2009) 2830.

[18] M.A. Bañares and G. Mestl, Adv. Catal., Vol. 52, 2009, p. 43.

[19] L.J. Burcham, G. Deo, X.T. Gao and I.E. Wachs, Top. Catal., 11 (2000) 85.

[20] E.V. Kondratenko, M. Cherian, M. Baerns, D.S. Su, R. Schlogl, X. Wang and I.E. Wachs, Journal of Catalysis, 234 (2005) 131.

[21] N. Magg, B. Immaraporn, J.B. Giorgi, T. Schroeder, M. Baumer, J. Dobler, Z.L. Wu, E. Kondratenko, M. Cherian, M. Baerns, P.C. Stair, J. Sauer and H.J. Freund, J. Catal., 226 (2004) 88.

[22] K. Devriendt, H. Poelman and L. Fiermans, Surf. Sci., 435 (1999) 734.

[23] R.P. Blum, H. Niehus, C. Hucho, R. Fortrie, M.V. Ganduglia-Pirovano, J. Sauer, S. Shaikhutdinov and H.J. Freund, Phys. Rev. Lett., 99 (2007).

[24] S. Agnoli, M. Sambi, G. Granozzi, C. Castellarin-Cudia, S. Surnev, M.G. Ramsey and F.P. Netzer, Surf. Sci., 562 (2004) 150.

[25] M. Della Negra, M. Sambi and G. Granozzi, Surf. Sci., 494 (2001) 213.

[26] M. Sambi, M. Della Negra and G. Granozzi, Surf. Sci., 470 (2000) L116.

[27] A.C. Dupuis, M. Abu Haija, B. Richter, H. Kuhlenbeck and H.J. Freund, Surf. Sci., 539 (2003) 99.

[28] M. Abu Haija, S. Guimond, Y. Romanyshyn, A. Uhl, H. Kuhlenbeck, T.K. Todorova, M.V. Ganduglia-Pirovano, J. Dobler, J. Sauer and H.J. Freund, Surf Sci, 600 (2006) 1497. 
[29] M. Abu Haija, S. Guimond, A. Uhl, H. Kuhlenbeck and H.J. Freund, Surf. Sci., 600 (2006) 1040.

[30] A. Bandara, M. Abu-Haija, F. Hobel, H. Kuhlenbeck, G. Rupprechter and H.J. Freund, Top. Catal., 46 (2007) 223.

[31] C. Kolczewski, K. Hermann, S. Gulmond, H. Kuhlenbeck and H.J. Freund, Surf. Sci., 601 (2007) 5394.

[32] J. Schoiswohl, S. Eck, M.G. Ramsey, J.N. Andersen, S. Surnev and F.P. Netzer, Surf. Sci., 580 (2005) 122.

[33] J. Schoiswohl, M. Sock, S. Eck, S. Surnev, M.G. Ramsey, F.P. Netzer and G. Kresse, Physical Review B, 69 (2004).

[34] J. Schoiswohl, S. Surnev, M. Sock, S. Eck, M.G. Ramsey, F.P. Netzer and G. Kresse, Physical Review B, 71 (2005).

[35] J. Middeke, R.P. Blum, M. Hafemeister and H. Niehus, Surf. Sci., 587 (2005) 219.

[36] H. Niehus, R.P. Blum and D. Ahlbehrendt, Physica Status Solidi a-Applied Research, 187 (2001) 151.

[37] H. Niehus, R.P. Blum and D. Ahlbehrendt, Surface Review and Letters, 10 (2003) 353.

[38] S. Kaya, Y.N. Sun, J. Weissenrieder, D. Stacchiola, S. Shaikhutdinov and H.J. Freund, J. Phys. Chem. C, 111 (2007) 5337.

[39] Y. Romanyshyn, S. Guimond, H. Kuhlenbeck, S. Kaya, R.P. Blum, H. Niehus, S. Shaikhutdinov, V. Simic-Milosevic, N. Nilius, H.J. Freund, M.V. Ganduglia-Pirovano, R. Fortrie, J. Dobler and J. Sauer, Top. Catal., 50 (2008) 106.

[40] G.S. Wong, M.R. Concepcion and J.M. Vohs, J. Phys. Chem. B, 106 (2002) 6451.

[41] T. Feng and J.M. Vohs, J. Catal., 221 (2004) 619.

[42] J.M. Vohs, T. Feng and G.S. Wong, Catal. Today, 85 (2003) 303.

[43] M. Calatayud, B. Mguig and C. Minot, Surf. Sci., 526 (2003) 297.

[44] A. Vittadini, M. Casarin, M. Sambi and A. Selloni, J. Phys. Chem. B, 109 (2005) 21766.

[45] T.K. Todorova, M.V. Ganduglia-Pirovano and J. Sauer, J. Phys. Chem. C, 111 (2007) 5141.

[46] M.M. Islam, D. Costa, M. Calatayud and F. Tielens, J. Phys. Chem. C, 113 (2009) 10740.

[47] J. Döbler, M. Pritzsche and J. Sauer, J. Phys. Chem. C, 113 (2009) 12454.

[48] V. Shapovalov and H. Metiu, J. Phys. Chem. C, 111 (2007) 14179.

[49] J.M. Sturm, D. Göbke, H. Kuhlenbeck and H.J. Freund, (2008) in preparation.

[50] J.M. Sturm, D. Göbke, H. Kuhlenbeck, J. Döbler, U. Reinhardt, M.V. GandugliaPirovano, J. Sauer, and H.-J. Freund, Phys. Chem. Chem. Phys., 11 (2009) 3290.

[51] G.S. Wong, D.D. Kragten and J.M. Vohs, J. Phys. Chem. B, 105 (2001) 1366.

[52] Q.G. Wang and R.J. Madix, Surf. Sci., 496 (2002) 51.

[53] G.S. Wong, M.R. Concepcion and J.M. Vohs, Surf. Sci., 526 (2003) 211.

[54] D.R. Mullins, M.D. Robbins and J. Zhou, Surf. Sci., 600 (2006) 1547.

[55] M. Baron, H.L. Abbott, O. Bondarchuk, D. Stacchiola, A. Uhl, S. Shaikhutdinov, H.-J. Freund, C. Popa, M.V. Ganduglia-Pirovano and J. Sauer, Angew. Chem. Int. Ed., 48 (2009) 8006.

[56] V.M. Ganduglia-Pirovano, C. Popa, J. Sauer, H. Abbott, A. Uhl, M. Baron, D. Stacchiola, O. Bondarchuk, S. Shaikhutdinov, H.-J. Freund, J. Am. Chem. Soc., 132 (2010) 2345.

[57] D.R. Mullins, P.V. Radulovic and S.H. Overbury, Surf. Sci., 429 (1999) 186.

[58] M. Baron, O. Bondarchuk, D. Stacchiola, S. Shaikhutdinov and H.-J. Freund, J. Phys. Chem. C, 113 (2009) 6042. 
[59] J.L. Lu, H.J. Gao, S. Shaikhutdinov and H.J. Freund, Surf. Sci., 600 (2006) 5004.

[60] M.F. Zhou and L. Andrews, J. Phys. Chem. A, 103 (1999) 2066.

[61] D. Göbke, Y. Romanyshyn, S. Guimond, J.M. Sturm, H. Kuhlenbeck, J. Döbler, U. Reinhardt, M.V. Ganduglia-Pirovano, J. Sauer and H.-J. Freund, Angewandte Chemie International Edition, 48 (2009) 3695.

[62] N. Magg, J.B. Giorgi, T. Schroeder, M. Baumer and H.J. Freund, J. Phys. Chem. B, 106 (2002) 8756.

[63] S. Guimond, M. Abu Haija, S. Kaya, J. Lu, J. Weissenrieder, S. Shaikhutdinov, H. Kuhlenbeck, H.J. Freund, J. Dobler and J. Sauer, Top. Catal., 38 (2006) 117.

[64] S. Guimond, J.M. Sturm, D. Gobke, Y. Romanyshyn, M. Naschitzki, H. Kuhlenbeck and H.J. Freund, J. Phys. Chem. C, 112 (2008) 11835.

[65] G.S. Wong and J.M. Vohs, Surf. Sci., 498 (2002) 266.

[66] M.V. Martinez-Huerta, J.M. Coronado, M. Fernandez-Garcia, A. Iglesias-Juez, G. Deo, J.L.G. Fierro and M.A. Bañares, J. Catal., 225 (2004) 240.

[67] S. Kaya, PhD Thesis, Humboldt-Universität zu Berlin, Berlin, 2007.

[68] C. Moisii, L.J. van de Burgt and A.E. Stiegman, Chem. Mater., 20 (2008) 3927.

[69] S. Schauermann, J. Hoffmann, V. Johane k, J. Hartmann and J. Libuda, Physical Chemistry Chemical Physics, 4 (2002) 3909.

[70] M. Trenary, Annual Review of Physical Chemistry, 51 (2000) 381.

[71] P. Dumas, M.K. Weldon, Y.J. Chabal and G.P. Williams, Surface Review and Letters, 6 (1999) 225.

[72] P.A. Redhead, Vacuum, 12 (1963) 203.

[73] V. Matolín, J. Libra, M. Skoda, N. Tsud, K.C. Prince and T. Skála, Surf. Sci., 603 (2009) 1087.

[74] J. Döbler, M. Pritzsche and J. Sauer, J. Am. Chem. Soc., 127 (2005) 10861.

[75] A. Goodrow and A.T. Bell, J. Phys. Chem. C, 111 (2007) 14753.

[76] A. Goodrow and A.T. Bell, J. Phys. Chem. C, 112 (2008) 13204. 


\section{Figure captions.}

Figure 1. STM images of $\mathrm{VO}_{\mathrm{x}}$ on $\mathrm{CeO}_{2}(111)$ thin films after annealing in oxygen to $300 \mathrm{~K}$ with vanadia loadings of $\sim 0.15 \mathrm{~V} / \mathrm{nm}^{2}$ (a), $\sim 0.70 \mathrm{~V} / \mathrm{nm}^{2}$ (b), and $\sim 4.3 \mathrm{~V} / \mathrm{nm}^{2}$ (c). Schematic of the structure for a vanadia monomer on ceria is shown in (d). STM images of samples (b) and (c) after annealing to $700 \mathrm{~K}$ are shown in (e) and (f), respectively. Insets show higher resolution images of the vanadia species such as monomers (a, b), dimers and trimers (b, c), and heptamers (f). Images were obtained using a tunneling bias and tunneling current of $2.2 \mathrm{~V}$ and $0.19 \mathrm{nA}$ (a), $3.0 \mathrm{~V}$ and $0.10 \mathrm{nA}(\mathrm{b}), 3.2 \mathrm{~V}$ and $0.035 \mathrm{nA}(\mathrm{c}), 3.1 \mathrm{~V}$ and $0.014 \mathrm{nA}(\mathrm{e})$, and $3.0 \mathrm{~V}$ and $0.11 \mathrm{nA}$ (f).

Figure 2. PE spectra of the $\mathrm{V} 2 \mathrm{p}_{3 / 2}$ core level for $\mathrm{VO}_{\mathrm{x}} / \mathrm{CeO}_{2}(111)$ samples are shown as a function of vanadia coverage (a) and as a function of sample treatment (b). Spectra were obtained using a photon energy (hv) of $620 \mathrm{eV}$, except for the top spectrum in (b) where $\mathrm{h} v=$ $660 \mathrm{eV}$. Deposition of vanadium and annealing was performed in an $\mathrm{O}_{2}$ ambient $\left(\sim 10^{-6}\right.$ mbar). The spectrum in (b) was obtained by dosing a saturation coverage of $\mathrm{CH}_{3} \mathrm{OH}$ at $\sim 160 \mathrm{~K}$ and annealing to $300 \mathrm{~K}$. Spectra are offset for clarity.

Figure 3. (a) IRA spectra showing the vanadyl $(\mathrm{V}=\mathrm{O})$ stretching region for $\mathrm{VO}_{\mathrm{x}} / \mathrm{CeO}_{2}$ as a function of vanadia coverage. Vanadia was deposited at $\sim 150 \mathrm{~K}$ in $10^{-6}$ mbar $\mathrm{O}_{2}$, annealed to room temperature in the same $\mathrm{O}_{2}$ ambient for 10 minutes, and then cooled to $100 \mathrm{~K}$ before acquisition of the spectra. Each spectrum is referenced to the $\mathrm{CeO}_{2}(111)$ sample. (b,c) IRA spectra of the same $\mathrm{VO}_{\mathrm{x}} / \mathrm{CeO}_{2}$ samples shown in panel (a) after exposure to $\sim 5 \mathrm{~L}^{\text {of }} \mathrm{CH}_{3} \mathrm{OH}$ at $300 \mathrm{~K}$. The spectra in (b) are referenced to the pristine ceria film, while the spectra in (c) are referenced to the corresponding pre-adsorption spectra in (a) to more clearly see consumption of the vanadyl band upon methanol adsorption.

Figure 4. STM images for $\sim 0.3 \mathrm{~V} / \mathrm{nm}^{2}$ on $\mathrm{CeO}_{2}(111)$ at $300 \mathrm{~K}$ (a) and after annealing to $450 \mathrm{~K}$ in the presence of $\mathrm{CH}_{3} \mathrm{OH}$ (b). The $20 \mathrm{~nm} \times 20 \mathrm{~nm}$ images were obtained using a tunneling bias of $3.0 \mathrm{~V}$ and a tunneling current of $0.2 \mathrm{nA}$ (a) and $0.02 \mathrm{nA}$ (b). In (a) the arrow highlights one of 
several vanadia monomers with a dark "halo". The simultaneous presence of vanadia monomers, dimers, and trimers is clearly seen in (b).

Figure 5. TPD spectra for $\mathrm{CH}_{3} \mathrm{OH}$ on $\mathrm{VO}_{\mathrm{x}} / \mathrm{CeO}_{2}$ as a function of vanadia coverage (a-d). Dashed lines indicate the raw signal for $\mathrm{CH}_{3} \mathrm{OH}(31 \mathrm{amu})$ desorption, while solid lines indicate $\mathrm{CH}_{2} \mathrm{O}$ desorption (i.e., the 29 amu signal corrected for the methanol cracking pattern).

Figure 6. IRA and TPD spectra are shown for low coverages of vanadia/ceria after vanadia deposition at $\sim 100 \mathrm{~K}$, annealing to room temperature for 10 minutes in an $\mathrm{O}_{2}$ ambient $\left(\sim 10^{-6}\right.$ mbar), and annealing to $700 \mathrm{~K}$ in the same $\mathrm{O}_{2}$ ambient. (a) Approximately $5 \mathrm{~L}$ of $\mathrm{CH}_{3} \mathrm{OH}$ was dosed at room temperature. Samples were cooled to $100 \mathrm{~K}$ before acquisition of each IR spectrum, which is referenced to the $\mathrm{CeO}_{2}(111)$ sample. (b) Dashed lines indicate the raw signal for $\mathrm{CH}_{3} \mathrm{OH}$ (31 amu) desorption, while solid lines indicate $\mathrm{CH}_{2} \mathrm{O}$ desorption (i.e., the $29 \mathrm{amu}$ signal corrected for the methanol cracking pattern). 

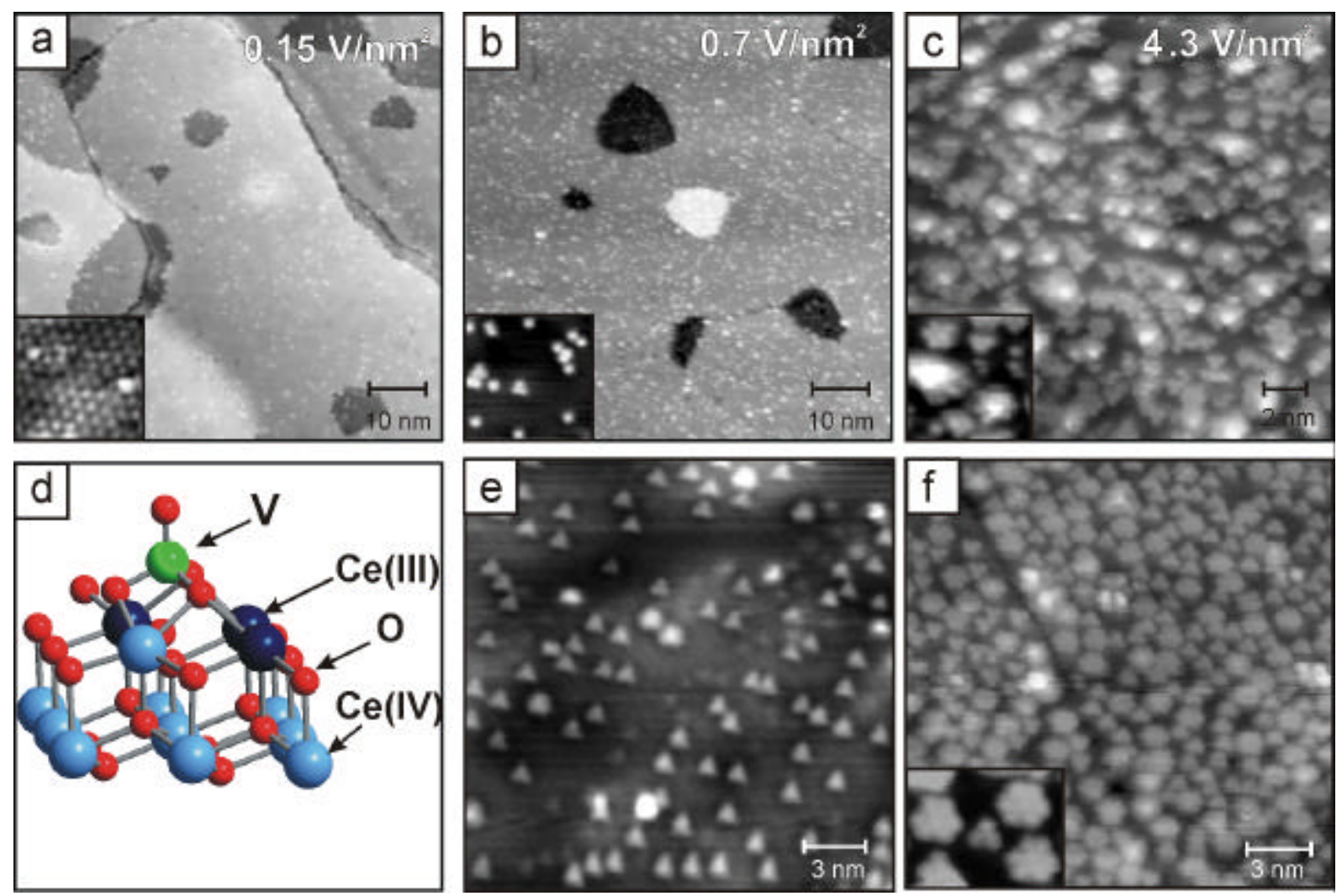

Figure 1 


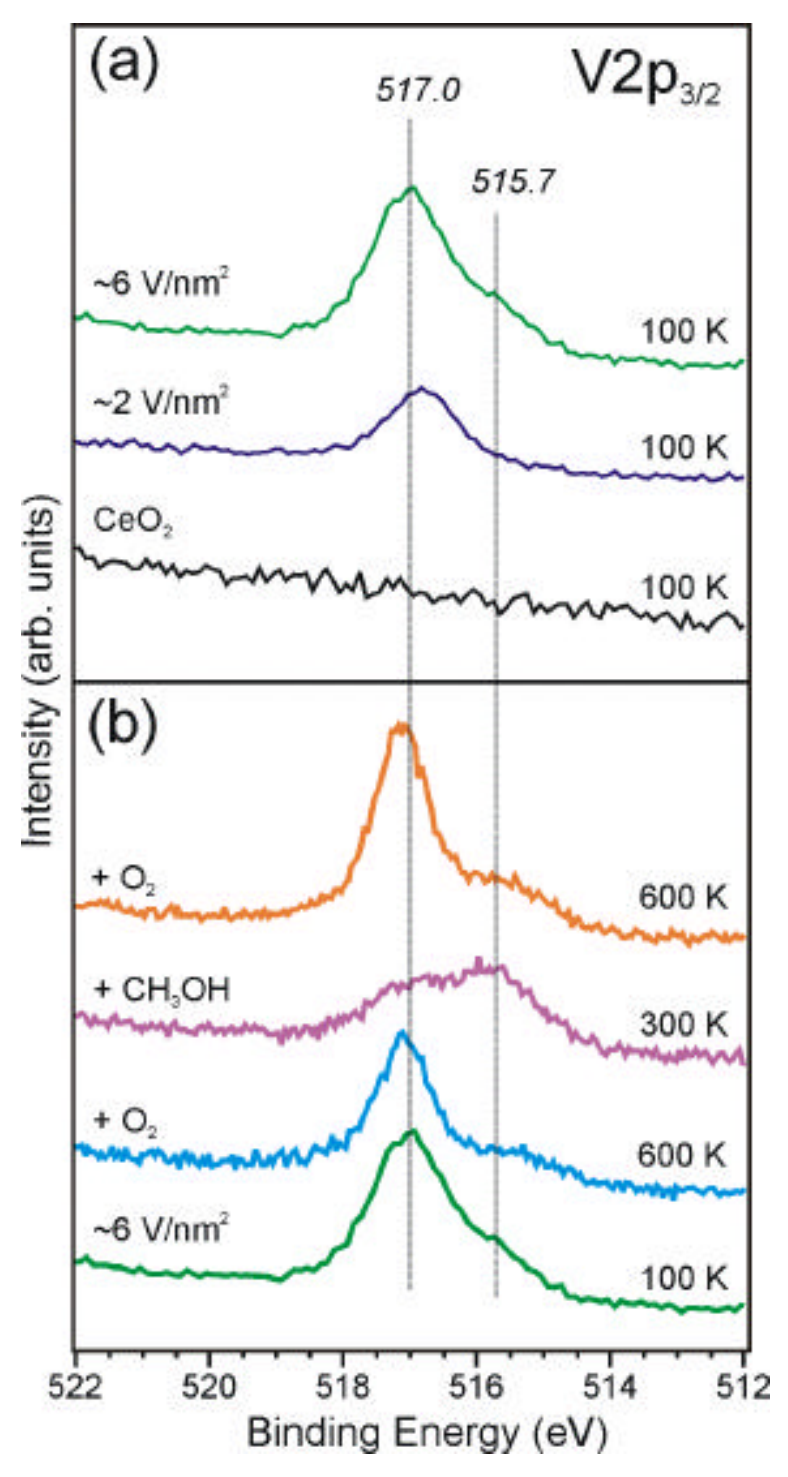

Figure 2 


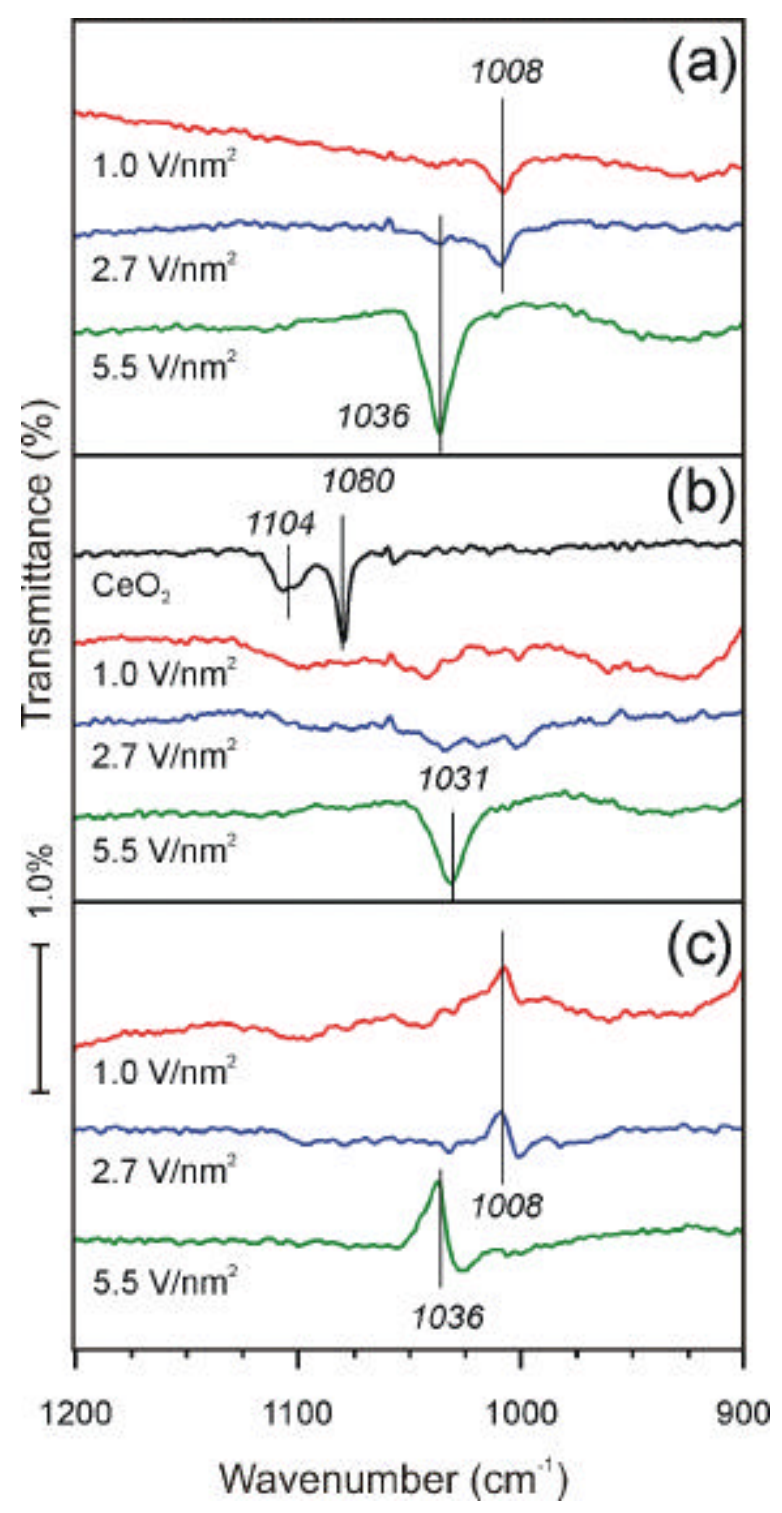

Figure 3 

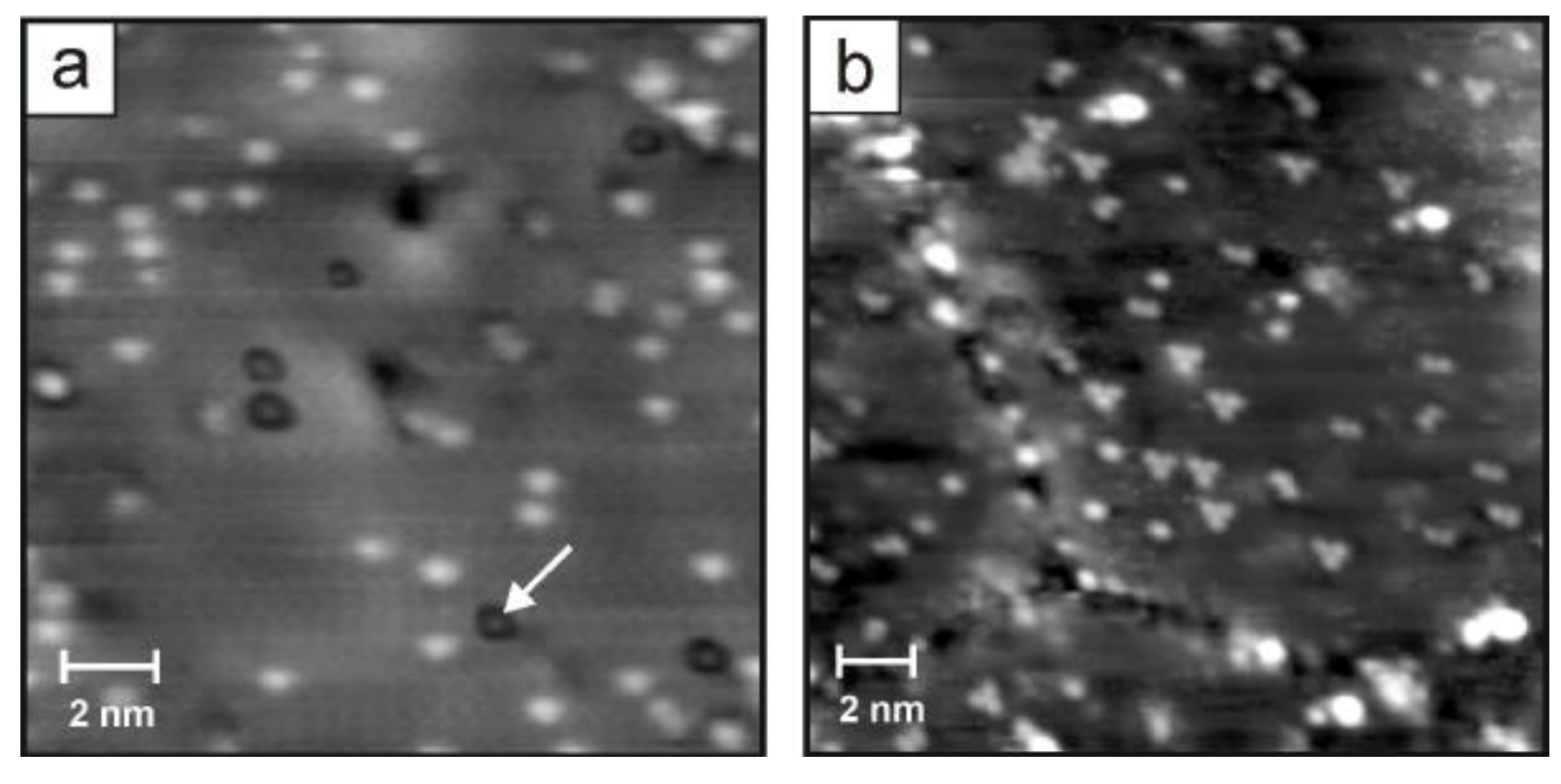

Figure 4 


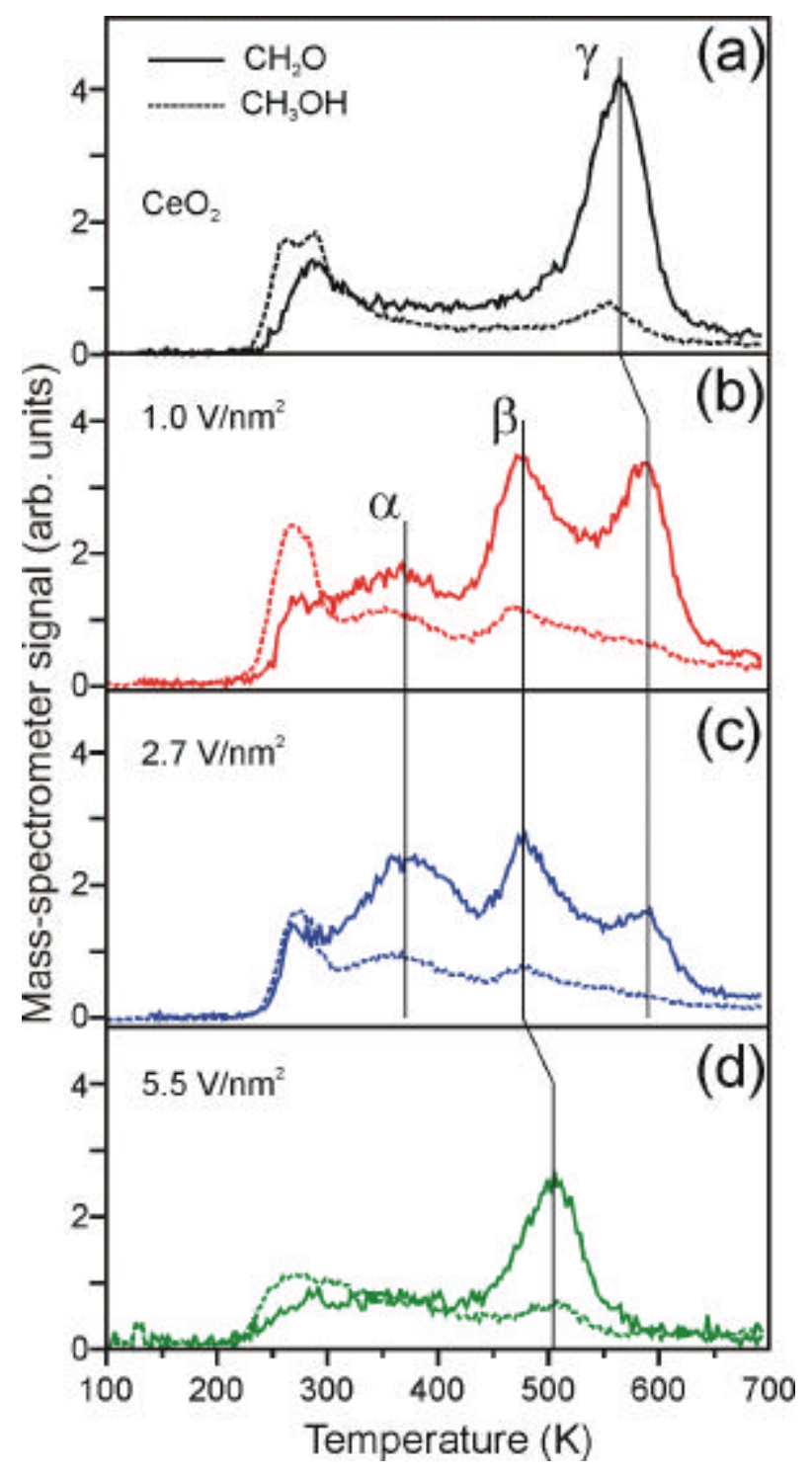

Figure 5 

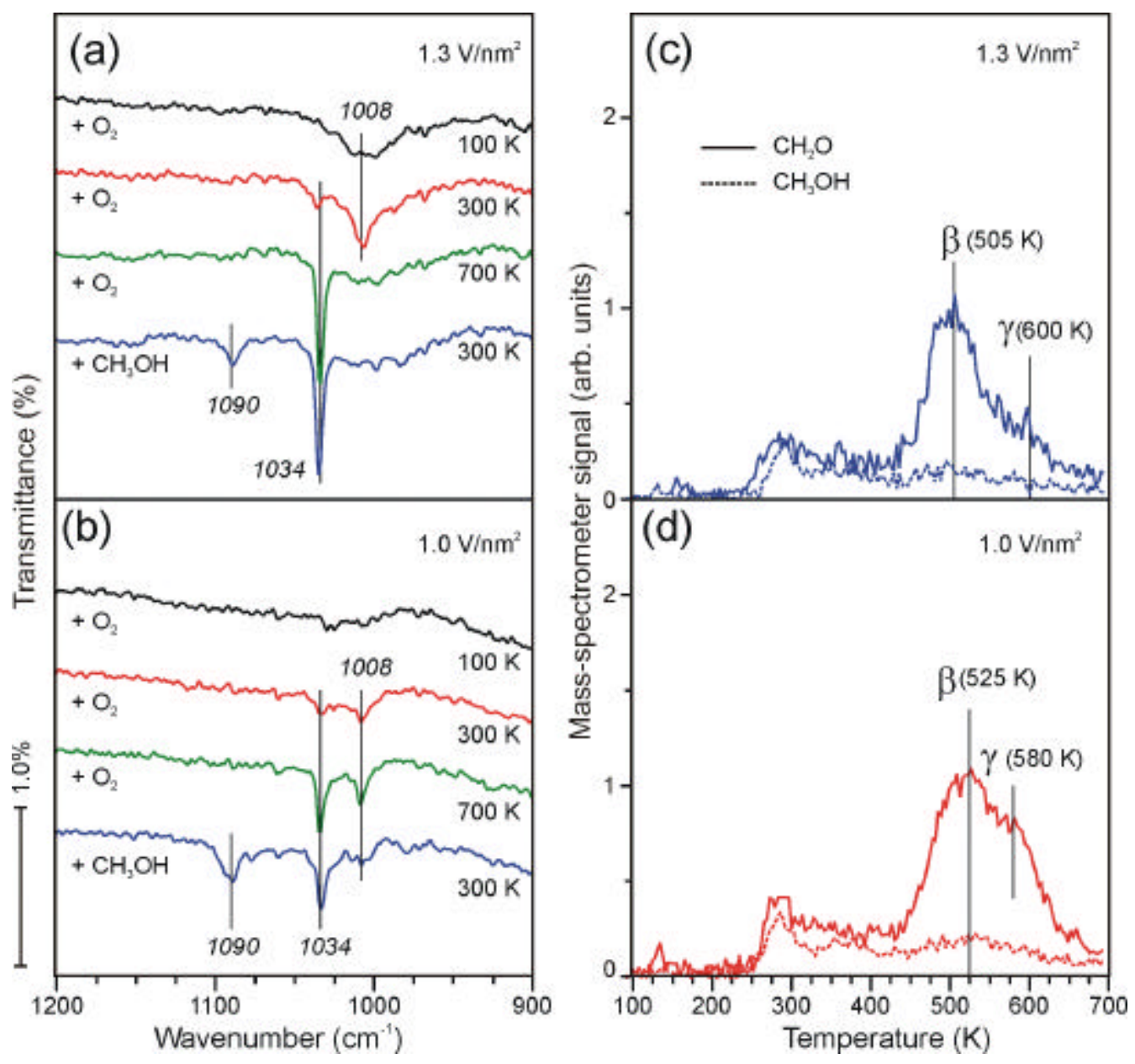

Figure 6 